\title{
An Investigation of Chinese Citizens' Core Literacy in the New Era
}

\author{
Lu Wenying \\ Xi’an Peihua University, Xi’an, Shaanxi, 710125, China
}

Keywords: new era, civic literacy, research

\begin{abstract}
The core literacy of future citizens is an important content to promote social development, which has attracted great attention from countries and regions. Combined the reality of global development with national conditions and history, countries and regions have put forward the content of core literacy for their own future citizens one after another. In order to propose more practical core literacy for Chinese citizens in the new era, we systematically analyze the citizens' core literacy requirements that have been proposed by various countries, and accordingly conclude top seven core literacy requirements-communication and cooperation, learning and lifelong learning, critical thinking, self-awareness and self-regulation, information literacy, creativity and problem solving, civic responsibility and social participation. A survey conducted in the two groups of college teachers and students shows that their attention don't get away from their actual living environment and scenes, from which we get that it is necessary to focus on the present and look forward to the future so as to more effective results.
\end{abstract}

\section{Background}

With the increasing competition among countries in comprehensive national strength, focusing on the economic development to improve civic literacy and cultivate talents with international competitiveness in this new century have become the common theme of the world in the pursuit of development. At the same time, return to people-oriented, promote public all-round and lifelong development, and push the social progress while meeting individual needs of self-realization, which in turn to achieve the harmonious unity of individual and social development, also have become the basic education appeal in the new era.

Our country is now in a new era under the president Xi Jinping, which also means that China has entered a moderately prosperous society. From the international influence to the globalization degree and to the development of technological information, it is no longer possible for us to hide into a small group to be unity. We must understand the countries and regions with different economic developments around the world, and learn their good practices on rational guidance of citizens' core literacy in the $21^{\text {st }}$ century when facing changes and future development, as well as governing the nation. Combined to our own national conditions, it is better to promote our citizens to adapt to the ever-changing new era, realize the pursuit of happy life, and achieve the common people and nation. In the process of actual national governance, push the common people to really feel the party and the nation's practical implementation of the mass line and mass viewpoint in the historical materialism.

The purpose of this study is to understand the expectations and needs for talents cultivation in China current public through an investigation on different groups and fields, to summarize the core literacy indicators from actual needs, and finally to provide an empirical basis for the purpose of establishing a set of core literacy framework suitable for students' development and at the same time meeting the current social needs and containing epochal and national character.

\section{Research Process}

\subsection{Overview}

So far, researches on core literacy which began in the 1990s have formed a mature theoretical framework and achieved abundant results. Among them, there is an expendable research space on 
core literacy area, taking content as the longitude and time as the latitude, and making stereoscopic reduction of the research status domestic and abroad in criss-crossing, which has great theoretical significance on innovative reform of education and teaching.

Based on the results of other researchers, we have searched for authoritative educational documents from different international organizations and economies, integrated their commonalities and differences of $21^{\text {st }}$ century literacy, and summarized the driving forces of core literacy into three categories, ten aspects in total: era and technological change ( globalization, knowledge age, technological development and information age), economic and social development ( economic growth, occupational needs, demographic changes, multiculturalism, environment and sustainable development), educational development (educational quality improvement, educational equality). Meanwhile, we have also analyzed the core literacy frameworks in the $21^{\text {st }}$ century of different countries, which aims to help citizens achieve a successful life and develop a sane society (such as OECD, etc.); aims at cultivating learning ability to lifelong learning (eg. EU, UNESCO and Taiwan, etc.); focusing on fostering creativity and entrepreneurship, pays attention to workplace needs in the $21^{\text {st }}$ century (sucha as P21, APEC and Canada); aims to develop core values and qualified citizens with a sense of responsibility (eg. Singapore, Hong Kong, China and Korea); and pays attention to the citizens' daily life and the quality of cultural leisure (such as Russia and Finland).

In short, because of the different original intentions and service objects in international organizations' framework and the differences in socio-economics development system and cultural characteristics of economic entities, the specific objectives of these frameworks will display slightly different, the literacy involved in each framework will be diverse, and the hierarchical relationships and presentations methods will vary as well.

The $21^{\text {st }}$ century core literacy frameworks of various international organizations and economies have comprehensiveness characteristics. From the basic judgments and overall understanding of the core literacy that future citizens should possess by various policy makers around the world, it combines 18 literacy in two dimensions, 9 of which are closely related to a specific field, including basic field literacy (6 items) and emerging field literacy (3 items); the other 9 items are universal literacy, pointing to higher-level cognition (3 items), personal growth (2 items), and social development (4 items).

\subsection{Research Design}

\subsubsection{Literature Search and Analysis}

By searching the literature and authoritative documents in international organizations and economies around the world, we refine and analyze the influencing factors and content of core literacy in the new era, that is, the commonality among them.

\subsubsection{Empirical Study}

The great value of the empirical study is that the core literacy framework formed can better integrate with the actual needs. Although the basic theoretical research can propose the theoretical structure and indicators of core literacy from the urgency perspective, there are still differences in the focus point of different countries when considering national conditions, especially economic development levels. Therefore, after the top-down combing effect via basic theories, it is necessary to further study the bottom-up investigation by means of empirical study, fully considering the socio-economic and cultural characteristics of the nation, the actual demand for talents, and the students' development status. Through interviews, questionnaires, and consultations, we have widely collected various views about core literacy from all parts of society, and selected indicators based on actual needs to verify, supplement and enrich the theoretical research. For example, the core literacy research in China is based on the requirements of talents development in the new era and the consideration of people-oriented to promote students' integrated and lifelong development. After the basic theoretical research, make a further empirical study on the group with outstanding achievements and significant influences in all sectors of society via interview and questionnaire methods, so as to select and come up with the most significant indicators of core literacy to meet the 
actual demand in China.

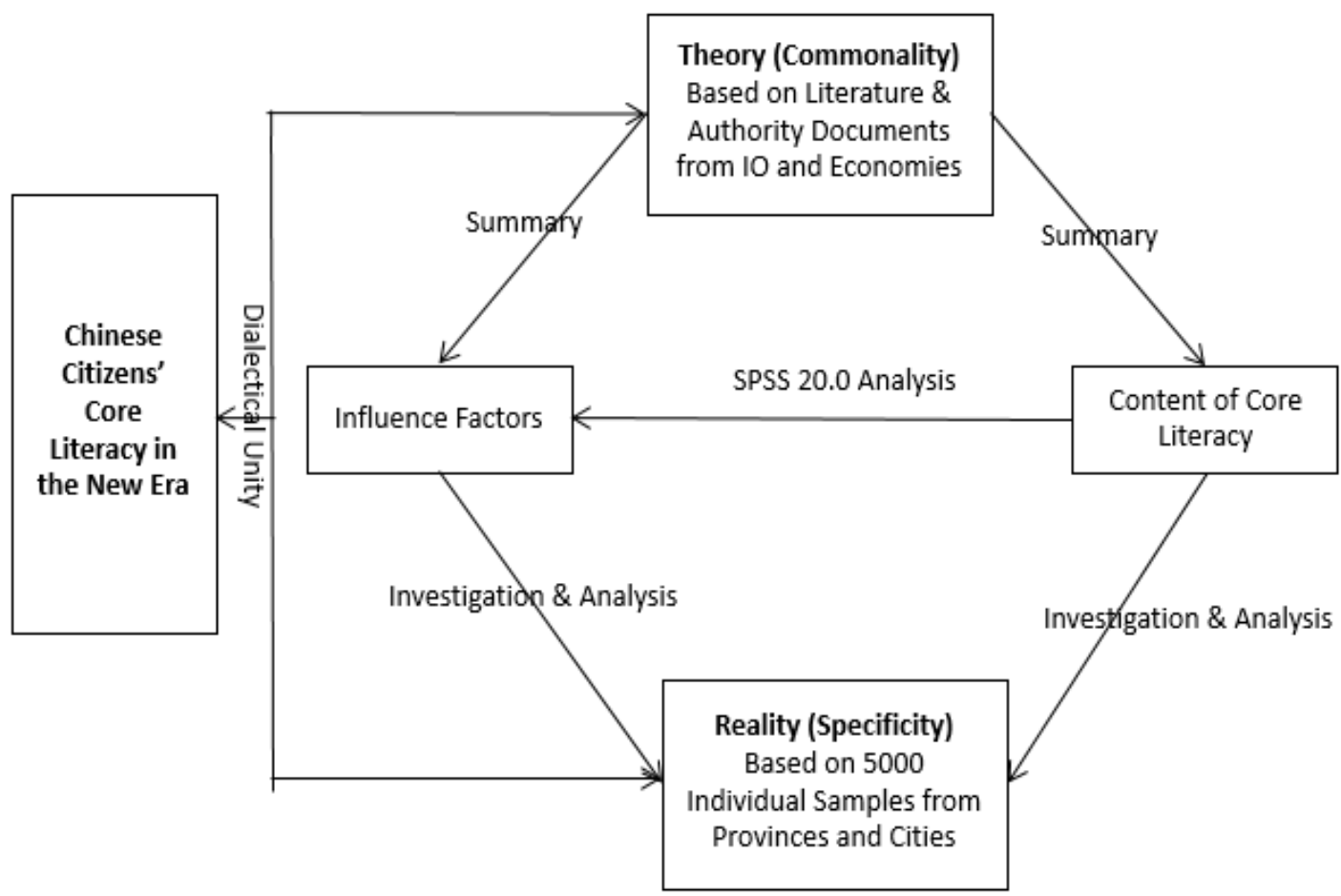

\section{Research Contents}

\subsection{Refining seven major performance of core literacy in different countries and economies}

With the help of Internet, comprehensively and deeply analyze the influencing factors of core literacy in the new era with a global perspective. Combine the relevant authoritative literature and extract keywords related to influencing factors of core literacy, put similar factors or those have same connotation together, perfect the influencing factors of core literacy, and then refine out seven major performance, which are communication and cooperation, learning and lifelong learning, critical thinking, self-awareness and self-regulation, information literacy, creativity and problem solving, civic responsibility and social participation. Then use this as a basis to design a questionnaire, and complete about 5,000 questionnaires and interviews among college teachers and students to obtain the overall situation of the main concerns and different focus points in various disciplines.

\subsection{Through questionnaires to understand the identity of main abilities of core literacy in young students}

After the questionnaire survey, as shown in Figure 1, we find that the top four abilities expected to improve from the students' overall data are communication and cooperation (87\%), self-awareness and self-regulation (74\%), creativity and problem solving (61\%), and learning and lifelong learning (61\%). However, the expectations in the students of School of Intelligent Science and Medical School are distinct with them in the students of whole schools. The main focuses of the students in School of Intelligence Science are communication and cooperation (89\%), creativity and problem solving (72\%), self-awareness and self-regulation (71\%), and learning and lifelong learning (58\%). While the situation in Medical School students are communication and cooperation (84\%), self-awareness and self-regulation (74\%), learning and lifelong learning (59\%), and creativity and problem solving (54\%). 


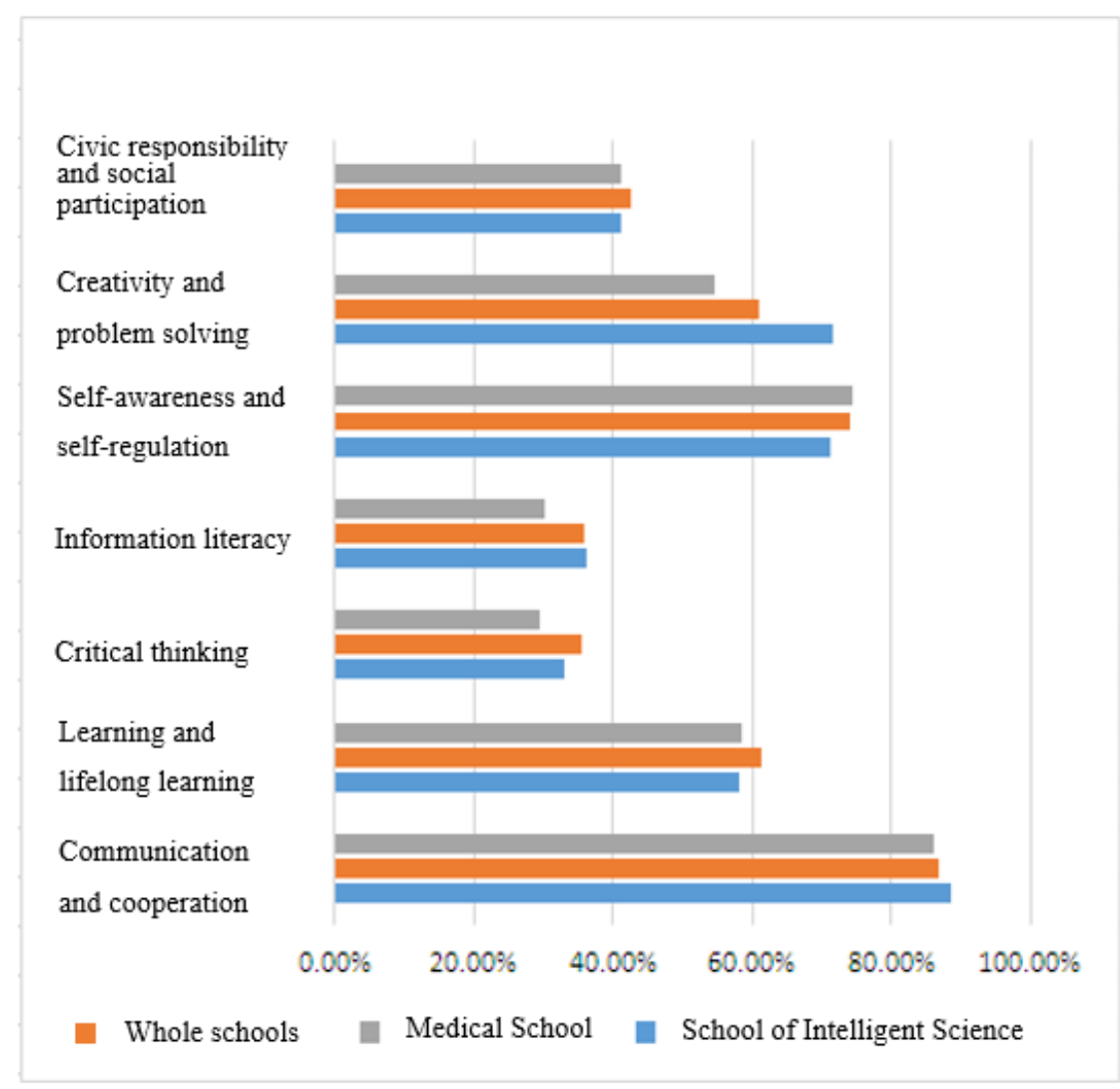

Figure 1 the ability of college students to expect improvement

From Figure 2, we can get to know different views of teachers and students. No teachers believe that the information literacy, creativity and problem solving, and civic responsibility and social participation are not important, while there are different proportions in teachers think that the other four abilities are not important. That is to say, one of the skills commonly recognized by all teachers and students is creativity and problem solving.

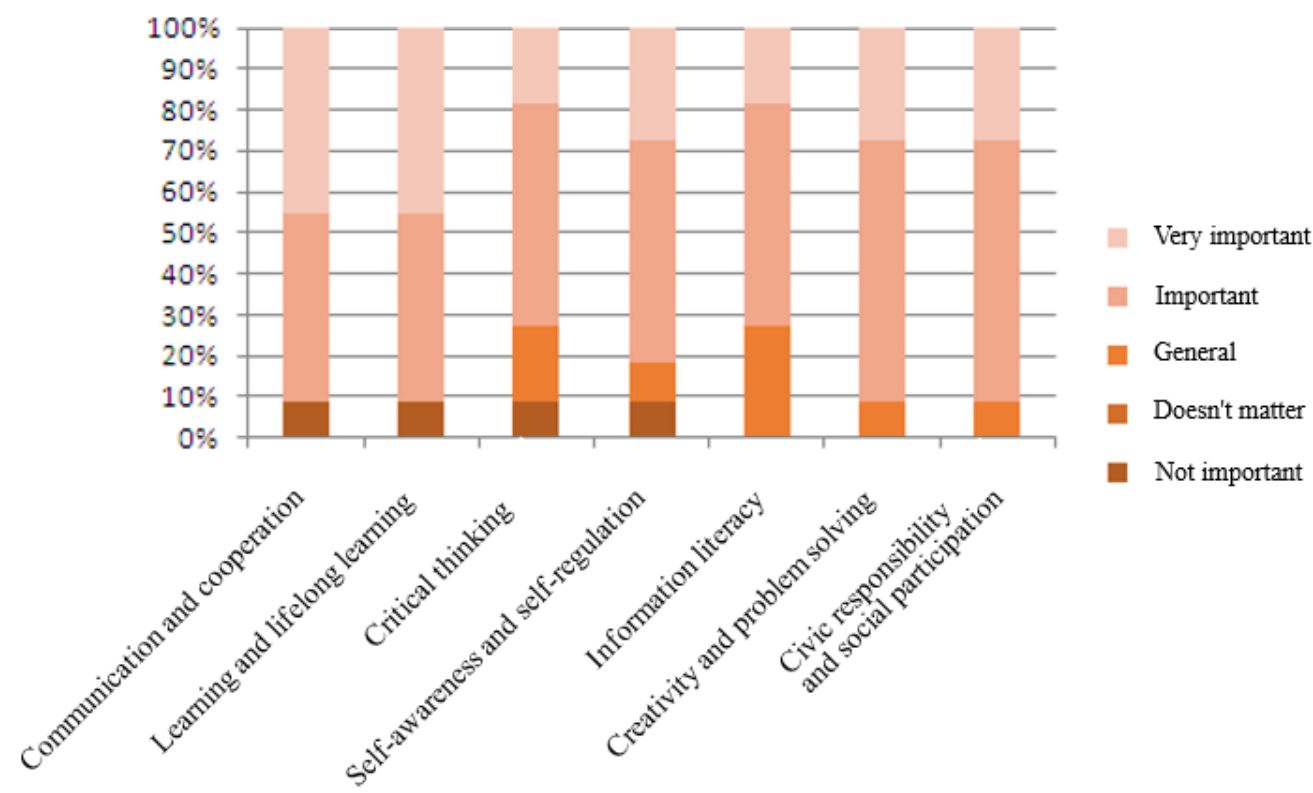

Figure 2 Teachers' attitudes towards Top 7

\subsection{Comparison analysis of influencing factors on different groups concerning different core literacy}

The previous survey statistics show that teachers and students pay different attention to the core literacy of TOP 7, among which teachers pay more attention to information literacy,and creativity 
and problem solving. Through our actual interview, we find that it has great relationship with teachers' real life and working environment. Because they have already joined the practical work which results in most of issues facing are to solve the problems happened in the real work and life, so the requirements for these three aspects are higher and more urgent. Therefore, when answering the questionnaire, they would care more about these contents naturally. Students are different, in contrast. They have not participated in the work, or they have not fully taken up the burden of life. Under the specific psychological needs in this age - more eager to interact with people, and influencing factors such as psychological contradictions, which pushes them to focus more on communication and cooperation, self-awareness and self-regulation, and learning and lifelong learning. Of course, the differences in different disciplines students when facing the TOP 7 perspectives also reflects the obvious impact of the discipline on students.

\section{Conclusion}

Through the TOP 7 perspectives of core literacy in future citizens proposed by various countries and regions, and empirical study via practical investigation, it can be concluded that the focus points of teachers and students cannot leave their studying disciplines, as well as living and working environment. Therefore, our education and guidance on civic core literacy must connect to their practical environment to effect greatly, which further helps the civic to better adapt to the future and service future society development. In the follow-up, we will extensively expand the research object to do more in-depth research.

\section{References}

[1] DeSeCo. (2005). The definition and selection of key competencies. Executive Summary (5-16). 2016.9.28, retrieved from http://www.oecd.org/pisa/35070367.pdf;

[2] OECD. (2013).OECD Skills Outlook 2013: First Results from the Survey of AdultSkills, OECD Publishing.2017.2.18, retrieved from

http://dx.doi.org/10.1787/9789264204256-en

[3] OECD. (2015).OECD Skills Outlook 2015: Youth, Skills and Employability, OECD Publishing.2017.2.18, retrieved from http://dx.doi.org/10.1787/9789264234178-en

[4] Hong Kong Education Bureau. (2001).Learn to learn - the direction of curriculum development. 2015.9.28, retrieved from http://cd1.edb.hkedcity.net/cd/TC/Content_2908/cappendix/app2.pdf

[5] Key Competences for lifelong learning - European reference framework. Luxembourg: Office for Official Publications of the European Communities. 2015.9.28, retrieved from http://www.alfa-trall.eu/wp-content/uploads/2012/01/EU2007-keyCompetencesL3-brochure.pdf 